\title{
DEBATES
}

\section{As lutas pelo passado em âmbito local: reflexões a partir do caso de Porto Alegre}

\author{
Disputes over the past in the local scope: reflections based on the \\ case of Porto Alegre
}

\section{Carlos Artur Gallo}

\section{Resumo}

Este estudo realiza uma reflexão sobre a dinâmica das políticas de memória em âmbito municipal. Para fazê-la, foi selecionado para análise o contexto da cidade de Porto Alegre, capital do Rio Grande do Sul. A análise proposta realiza um panorama das principais medidas que foram implementadas e/ou discutidas em âmbito local para promover o resgate da memória sobre o período da ditadura civil-militar (1964-1985), focando-se em um caso específico cujos principais desdobramentos se deram a partir de 2014.

\section{Palavras-chave}

Ditadura Civil-Militar (1964-1985); Políticas de Memória; Porto Alegre.

\section{Abstract}

This study reflects on the dynamics of politics of memory at the municipal level. To do so, the context of the city of Porto Alegre, capital of Rio Grande do Sul, was selected for analysis. The proposed analysis provides an overview of the main measures that have been implemented and/or discussed at the local level to promote the recovery of memory about the period of the civil-military dictatorship (1964-1985), focusing on a specific case whose main developments occurred from 2014 on.

\section{Keywords}

Civil-Military Dictatorship (1964-1985); Politics of Memory; Porto Alegre. 


\section{Introdução ${ }^{1}$}

A transição à democracia brasileira, realizada entre os anos de 1974 e 1985, é conhecida como um dos processos transicionais mais longos entre os países que foram redemocratizados no contexto da $3^{a}$ onda de democratizaçóes (HUNTINGTON, 1994). Lenta, gradual e segura, conforme arquitetada pelos setores civis-militares que estavam no poder desde o Golpe de 1964, a transição no país foi iniciada por integrantes do regime autoritário que se anteciparam a uma série de fatores que poderiam abalar a manutenção da ditadura, como a crise internacional do petróleo, que abalaria o chamado "milagre econômico". Propondo uma distensão controlada, esses setores conseguiram determinar os rumos do processo político, ainda que náo pudessem prever todos os seus acontecimentos (ARTURI, 2001; CODATO, 2005; GUGLIANO e GALLO, 2013).

Justamente devido ao alto controle que os setores alinhados à ditadura tiveram sobre o processo transicional, observa-se que a capacidade de ruptura que se realiza entre práticas e instituiçóes influenciadas pelo autoritarismo na construção da nova democracia foi bastante reduzida. Como consequência, uma série de legados autoritários se mantiveram no cenário político brasileiro, influenciando os rumos da política mesmo passadas décadas desde que o último dos ditadores-presidentes encerrou seu mandato (GALLO e GUGLIANO, 2014).

Independentemente do modo como ocorreu, o final de regimes autoritários sejam eles as ditaduras de inspiração nazi-fascistas europeias, sejam as ditaduras de Segurança Nacional instaladas no Cone Sul no contexto da Guerra Fria - tem sido acompanhado pela intensificação de demandas por memória, verdade e justiça. Há vinte ou trinta anos, não era frequente utilizar termos como "justiça de transição" e "políticas de memória" para abordar o tema dentro e fora da academia. Hoje, a realidade é diferente, tendo se consolidado uma agenda de pesquisas que problematiza as diferentes medidas e estratégias que vêm sendo implementadas em países que

\footnotetext{
${ }^{1}$ Este artigo é uma versão revista, ampliada e atualizada do trabalho apresentado no IV Colóquio Internacional Memória e Patrimônio e da palestra proferida durante o 9o Simpósio Internacional Memória e Patrimônio, eventos promovidos pelo Programa de Pós-Graduação em Memória Social e Patrimônio Cultural da Universidade Federal de Pelotas (UFPel). Os eventos referidos foram realizados, respectivamente, em novembro de 2018 e em maio de 2019, e a versão do texto que deu origem a este artigo foi publicada no e-book Memória \& Patrimônio - Volume 3 (Pelotas: Editora da UFPel, 2020), no qual foram publicados os trabalhos apresentados no colóquio realizado em 2018.
} 
passaram por regimes autoritários para lidar com o saldo da repressão e estabelecer uma memória sobre esses períodos.

Em linhas gerais, este estudo realiza uma reflexão sobre a dinâmica das políticas de memória em âmbito municipal. Para fazê-lo, foi selecionado para análise o contexto da cidade de Porto Alegre, capital do Rio Grande do Sul. A análise proposta realiza um panorama das principais medidas que foram implementadas e/ou discutidas em âmbito local para promover o resgate da memória sobre o período da ditadura, focando-se em um caso específico cujos principais desdobramentos se deram a partir de 2014. Tratase da mudança de nome de uma das principais vias de acesso à cidade, que até então fazia homenagem a um dos ditadores-presidentes que governou o país durante a ditadura (Castelo Branco, ditador-presidente entre 1964 e 1966), e das reviravoltas ocorridas a partir de agosto de 2018 via decisão judicial.

Considerando o exposto, questiona-se: O que explica os recuos na trajetória das políticas de memória implementadas na cidade de Porto Alegre? A hipótese que guia este estudo sugere que o modo como se deu a transição à democracia no Brasil gerou legados autoritários que, no presente, influenciam diretamente a forma como tais políticas são implementadas no país, inclusive em âmbito local. No que se refere à metodologia utilizada, trata-se de uma análise essencialmente qualitativa. A mesma foi elaborada com base em revisáo de literatura especializada sobre o tema, combinada com pesquisa documental (fontes oficiais) e complementada com a seleção e compilaçáo de informaçôes divulgadas na grande mídia.

Organizado em duas seçóes, o artigo apresenta, na primeira delas, elementos teórico-conceituais essenciais à reflexão sobre o tema proposto. $\mathrm{Na}$ segunda seção, menciona-se as principais políticas de memória implementadas em âmbito local na cidade de Porto Alegre, focando-se na descrição dos fatos envolvendo a mudança de nome do logradouro ocorrida em 2014. Na conclusão, a partir dos elementos apresentados, expóe-se os motivos pelos quais a disputa se intensificou nos últimos anos, ocorrendo, via Poder Judiciário, a volta do nome antigo para a avenida.

\section{Justiça de transição e politicas de memória: uma tarefa pendente na construção das novas democracias}

Lembrar e esquecer são atos cotidianos. Todos e todas lembram e esquecem de algo, deliberadamente ou não, no dia a dia. Em termos analíticos, o que significa falar da memória e do esquecimento? Qual o seu significado para pensar a dinâmica política? $\mathrm{O}$ debate e análise sobre as medidas implementadas em contextos políticos iniciados 
após regimes autoritários estão diretamente relacionados à compreensão de três aspectos teórico-conceituais: uma compreensão do que significa memória, o enquadramento da memória nos marcos do conceito "justiça de transição" e a análise daquelas que podem ser consideradas como "políticas de memória".

Uma reflexão sobre o conceito de memória e seus significados históricos, culturais, sociais e políticos pode ser feita a partir do estudo do sociólogo francês Maurice Halbwachs (2006). Um primeiro aspecto a ser destacado da análise de Halbwachs seria a ideia de que não existe, propriamente, uma memória, no singular, mas sim memórias, no plural, que coexistem. Existem memórias individuais, coletivas e históricas. Todas elas são construídas de modo relacional, isto é, representam as interaçôes humanas em torno da disputa sobre o que vai ser lembrado, como e por qual razão.

Parciais, todas as memórias o são, visto que não seria possível representar o todo. Mas, ainda conforme Halbwachs, e embora o próprio autor reconheça os limites da categoria por ele esboçada, a memória histórica se diferencia essencialmente das demais (a individual e a coletiva) por uma razão: ela representa aquilo que é fixado, oficializado através da atribuição de significados, e é unificada mediante o estabelecimento de versóes a priori incontornáveis de um fato ou de um conjunto de fatos. Memórias individuais e coletivas, portanto, são mais fluidas que a memória histórica.

Qual o significado disso para pensar a política? Em linhas gerais, é possível dizer que a fixação de sentidos sobre o passado ou, em outras palavras, e retoma-se aqui a análise de Paul Ricoeur (2007), a tensão entre memória e esquecimento, constitui um dilema político resolvido constantemente. O que se lembra, como, quem decide e como decide o que será oficializado sobre determinada conjuntura política, são perguntas que evidenciam o processo de lutas pelo passado descrito por Elizabeth Jelin (2017). Objetos de lutas, disputas sociais e políticas, as memórias (e o esquecimento) envolvem processos subjetivos de construção de significados e, conforme a autora, é importante observar quem são os atores que dão sentido ao passado.

Quando fala sobre os atores sociais e políticos que, envolvidos nas disputas em torno da memória sobre um período, dão sentido ao passado, Jelin (2017) comenta que as lutas travadas são realizadas por pessoas e instituiçóes. Pessoas que podem ser testemunhas oculares daquilo a que se quer atribuir sentido. Pessoas que podem não ter vivenciado aquilo que se quer narrar. Instituições públicas que precisam estabelecer uma versão sobre o que ocorreu. É a compreensão, precisamente, do papel 
desempenhado pelas instituiçóes nas disputas pelas memórias de um período, que pode ser realizada a partir do enquadramento do tema no conceito de "justiça de transiçâo" ou "justiça transicional".

O que é a justiça de transição? Em linhas gerais, a justiça de transição é um conceito recente, criado na década de 1990 pela pesquisadora Ruti Teitel, e que foca no uso, na instrumentalização do direito em circunstâncias excepcionais, se referindo à justiça (e seus mecanismos) adaptada para sociedades que tenham passado ou estejam passando por períodos marcados pela violência política - neste sentido: Ambos (2009); Quinalha (2013). Dito de outra forma, se refere ao Estado e suas instituiçóes atuando com vistas à promoçáo dos direitos humanos e ao fortalecimento de instituiçóes e práticas democráticas.

Complexa, a justiça transicional constitui uma tarefa bidimensional. É retrospectiva e, ao mesmo tempo, prospectiva. Retrospectiva porque abrange mecanismos criados para resgatar a memória de um período marcado por violaçóes aos direitos humanos, recompondo o passado, estabelecendo aquilo que de fato ocorreu e que, muitas vezes, foi não só silenciado por um regime autoritário, mas também adulterado em seu nome. É também prospectiva na medida em que busca fixar as bases para a apuraçáo de responsabilidades, para o julgamento daqueles que estão envolvidos com a repressão praticada e, em última análise, para a não repetição.

Intimamente relacionada ao conceito de justiça de transição, encontra-se a concepção de "políticas de memória". O que são políticas de memória? De uma maneira bastante objetiva, pode-se dizer, seguindo o estudo de Juan Mario Solís Delgadillo (2015), que elas são políticas públicas através das quais governos lidam com problemas relacionados à memória. Sendo mais específico, políticas de memória se referem às instituiçôes políticas sendo responsáveis por dirimir conflitos relacionados a um período histórico determinado (SOLÍS DELGADILLO, 2015, p. 39).

Podendo ser, portanto, consideradas como uma resposta do sistema político para satisfazer as demandas por memória, verdade e justiça que são encabeçadas sobretudo por movimentos de vítimas da repressão, essas políticas conciliam: os direitos das vítimas (a ideia de reparação), os direitos da sociedade (a ideia de que todos e todas têm o direito a saber, conhecer o passado), a importância da estabilidade democrática e do Estado de direito (SOLÍS DELGADILLO, 2015, p. 42-45). Políticas de memória, assim, podem ser medidas implementadas em qualquer nível da federação. Seja em âmbito nacional, seja em âmbito estadual ou municipal. 
Políticas em âmbito nacional, pensando-se no caso brasileiro para apresentar exemplos, podem ser a Comissão Nacional da Verdade e leis que previram a concessão de reparação às vítimas da ditadura (Lei no 10.521/2002) ou aos seus familiares (Lei no 9.140/1995). Medidas em âmbito local podem, à primeira vista, parecer menos tangíveis, mas, na prática, podem ser visualizadas na implementação de medidas bastante variadas, abrangendo desde construção de um memorial, uma praça ou qualquer espaço que faça alusão ao período autoritário, até a troca do nome de uma rua ou instituição de ensino que fora batizada em homenagem a alguém responsável por violaçóes aos direitos humanos.

\section{Avenida da Legalidade e da Democracia: a construção de uma política de memória em âmbito local}

Como foi visto na seção anterior, políticas de memória fazem parte das medidas de justiça de transição que vêm sendo implementadas em países que tenham passado por um regime/período autoritário e/ou marcado por massivas violaçôes aos direitos humanos, podendo variar bastante no tocante ao seu formato. Isto é, podem envolver reparação pecuniária (financeira sob diferentes formas, tais como o pagamento de indenizaçóes em parcela única, a fixação de uma pensão, entre outras), podem constituir medidas simbólicas, entre outras.

Uma medida simbólica, no sentido mencionado, é a alteração da denominação de logradouros e lugares públicos que tenham sido batizados para homenagear pessoas ou eventos relacionados a um período autoritário. Numa perspectiva abstrata, pode-se dizer que medidas como as referidas poderiam ser realizadas desde o fim das ditaduras e retorno à democracia. Bastaria, para tanto, que os governos que se sucederam ao regime autoritário formulassem políticas com vistas ao tratamento do tema, bem como que setores interessados na sua realização se articulassem demandando algo nesse sentido do sistema político ${ }^{2}$.

$\mathrm{Na}$ Argentina, por exemplo, medidas em âmbito local vêm sendo implementadas desde a década de 1990. Lá, em várias cidades do país existem praças e

\footnotetext{
${ }^{2}$ Em Portugal, após a Revolução dos Cravos ter sido iniciada, no dia 25 de abril de 1974, a ponte sobre o Tejo que liga as cidades de Lisboa e Almada foi rebatizada. De "Ponte Salazar", uma homenagem ao ditador português, a estrutura sobre o rio passou a ser denominada "Ponte 25 de Abril", simbolizando a mudança de perspectivas políticas para o país, que passara por décadas sob um regime autoritário. $\mathrm{Na}$ Espanha, décadas após o final do regime franquista, ainda não há consenso sobre o que deve ser feito com alguns símbolos da ditadura, como é o caso, entre outros, do Arco da Vitória (Arco de la Victoria), construído em Madri na década de 1950.
} 
ruas batizadas em homenagem às vítimas da ditadura, bem como homenageando os principais grupos articulados em torno do tema, como a Associação das Máes da Praça de Maio ou as Avós da Praça de Maio. No Brasil, algo semelhante já ocorrera antes dos anos 2000, mas, a partir de dezembro de 2009, quando ocorreu o lançamento da $3^{\mathrm{a}}$ edição do Programa Nacional dos Direitos Humanos (PNDH-3), pôde-se observar uma mudança de paradigma no tocante ao modo como se lida com o tema ${ }^{3}$.

$\mathrm{Na}$ nova edição do PNDH-3, elaborado no segundo mandato do presidente Luiz Inácio Lula da Silva (2006-2010), houve uma expansáo no que tange ao tratamento do tema da memória da repressão política no país, sendo destinado a tal tema um eixo específico do documento: o Eixo Orientador VI - Direito à Memória e à Verdade. Sobre políticas de memória em âmbito local, e após alteraçóes realizadas na redação original do programa (via Decreto 7.177, de 12 de maio de 2010), foi previsto:

Art. 5o As açôes programáticas "c" e "d" do Objetivo Estratégico I Suprimir do ordenamento jurídico brasileiro eventuais normas remanescentes de períodos de exceçâo que afrontem os compromissos internacionais e os preceitos constitucionais sobre Direitos Humanos - da Diretriz 25: Modernização da legislação relacionada com promoção do direito à memória e à verdade, fortalecendo a democracia, do Anexo do Decreto $\mathrm{n}^{\mathrm{o}}$ 7.037, de 2009, passam a vigorar com as seguintes redaçóes:

“c) Fomentar debates e divulgar informaçóes no sentido de que logradouros, atos e próprios nacionais ou prédios públicos não recebam nomes de pessoas identificadas reconhecidamente como torturadores. " (NR)

“d) Acompanhar e monitorar a tramitação judicial dos processos de responsabilização civil sobre casos que envolvam graves violaçôes de direitos humanos praticadas no período fixado no art. $8^{\circ}$ do Ato das Disposiçôes Constitucionais Transitórias da Constituição de 1988. ." (NR)

\footnotetext{
${ }^{3}$ A publicação da nova versão do $\mathrm{PNDH}$, em dezembro de 2009, gerou uma série de polêmicas a respeito de alguns eixos do documento. Disposiçóes sobre o aborto, tratado como uma questão de saúde pública, sobre direitos para a população LGBT e, especialmente, recomendaçôes em torno do tema da ditadura civil-militar no país, entre as quais a previsão da criação de uma Comissão Nacional da Verdade, foram duramente atacadas na opiniáo pública nos primeiros meses do ano de 2010. Como resultado das pressóes e polêmicas, o Governo Lula recuou e alterou o texto original do PNDH-3. Maiores detalhes podem ser encontrados em Gallo (2015).
} 
Com o PNDH-3 constituía-se uma mudança no sentido de que a implementação de medidas locais deixava de ser uma possibilidade abstrata, dependente da boa vontade dos governantes e da capacidade de articulação dos movimentos sociais. Passava a ser uma possibilidade mais concreta, já que tais medidas passavam a ser consideradas não uma obrigação, mas algo recomendável, inseridas num plano de metas para os direitos humanos.

Em Porto Alegre, algumas medidas com vistas ao resgate/preservaçáo da memória sobre o período da ditadura foram debatidas e, eventualmente, implementadas, antes mesmo da existência das recomendaçóes do PNDH-3. Exemplos disso podem ser encontrados na década de 1990, quando uma rua residencial foi batizada em homenagem a Luiz Eurico Tejera Lisbôa, desaparecido político pela ditadura na década de 1970 , bem como na criação do monumento-memorial em homenagem aos gaúchos mortos e desaparecidos no período, inaugurado em 1995, durante a gestão de Tarso Genro (PT/RS) na prefeitura, mas cuja criação se deu em 1994, por iniciativa da (à época) vereadora Maria do Rosário (PT/RS).

A rua em homenagem ao militante desaparecido pela repressão e o monumento, ambos constituindo medidas implementadas na década de 1990, poucos anos após o final da ditadura, foram criticados constante e publicamente por familiares das vítimas e organismos de direitos humanos. Ainda que reconheçam a importância das medidas, pondera-se a capacidade de que o objetivo delas, isto é, contribuir para o não esquecimento e a não repetição, seja atingido. Afinal, a rua batizada em homenagem a Luiz Eurico T. Lisbôa fica muito distante do Centro da cidade, caracterizando uma memória frágil, uma vez que dificilmente as pessoas que transitam pelo local irão parar para averiguar quem deu nome à rua. Soma-se a isso o fato de ser uma via pública essencialmente residencial, o que reduz bastante a circulação de pessoas.

O monumento-homenagem inaugurado em 1995, por sua vez, pode ser criticado sobretudo devido ao seu formato. A localização no Parque Marinha do Brasil, próxima a um shopping e num ponto de tráfego intenso de veículos que deslocam no sentido bairro-centro-bairro, é boa e, à primeira vista, até mesmo privilegiada. $\mathrm{O}$ problema é que tal localização não favorece a aproximação de pessoas, não havendo nem mesmo calçamento no local. O formato do monumento, por fim, potencializa a dificuldade de que o mesmo cumpra seu objetivo. A localização da inscrição na qual se explica o seu motivo de criação e a lista de gaúchos mortos e desaparecidos pela ditadura 
é estrategicamente limitada, uma vez que se encontra na parte traseira do monumento, dificultando sua visualização.

Nos últimos anos, o memorial encontra-se bastante degradado. Feito de aço naval, está visivelmente enferrujado, a vegetação ao redor está com frequência malcuidada, e o monumento possui muitas pichaçôes. Como observado por Caroline Silveira Bauer (2015), o monumento é visível e, ao mesmo tempo, invisível. Por consequência, sua função de catalizador da memória torna-se passível de questionamento.

A partir da publicação do PNDH-3, o contexto em que se discute a implementação de medidas como as que foram mencionadas é outro. Por um lado, há um programa nacional recomendando a implementação de medidas simbólicas em nível municipal, por outro, há a movimentação política que resulta na aprovação da Lei no $12.528 / 2011$, que criou a Comissão Nacional da Verdade. Numa conjuntura presumidamente mais favorável ao enfrentamento do tema "memória da repressão" é que se desenvolveu a discussão sobre a mudança de nome da avenida que dá acesso ao centro da cidade de Porto Alegre, considerada a principal via de acesso tanto para quem se desloca pela regiáo metropolitana como para quem se desloca desde cidades do interior. Oficialmente batizada Avenida Presidente Castelo Branco e popularmente chamada apenas de "Castelo Branco", essa avenida teria sua denominaçáo tornada alvo de disputas e polêmica a partir de 2011, quando a bancada do PSOL ingressou com uma primeira tentativa, sem êxito, de mudança do nome do logradouro (MENEGHETTI, 2011).

$\mathrm{Na}$ ocasião (dezembro de 2011), o projeto de lei foi derrotado por 16 votos contrários à mudança, 12 a favor e 8 abstençôes/ausências. Chama a atenção o fato de que parte dos vereadores que foram contrários à proposta e/ou se abstiveram de votar eram filiados a partidos supostamente sensíveis ao tema: o PDT e o PTB, "herdeiros" que disputam o legado trabalhista, e o PMDB, partido sucessor do MDB, oposição à ditadura. Durante a votação do projeto, conforme matéria do Jornal do Comércio, "Poucos parlamentares elogiaram o governo do ex-ditador Castelo Branco, a maioria de partidos sucedâneos da Arena (PP e DEM)” (MENEGHETTI, 2011).

Na mesma conjuntura em que foi articulada essa primeira tentativa de mudança do nome da Avenida Castelo Branco, a cidade seria palco, ainda, de outros dois fatos relacionados à repressão praticada a partir do golpe civil-militar. $\mathrm{O}$ primeiro fato se refere à inauguração, em agosto de 2011, do monumento homenageando o sargento Manoel Raymundo Soares, morto pelo DOPS gaúcho em 1966 (NATUSCH, 2011). 
O segundo fato marcante foi a identificação, em maio de 2012, de um centro clandestino de repressáo (o "Dopinha"), que funcionou em um casarão localizado numa área privilegiada, próxima do Centro da cidade.

O monumento em homenagem a Manoel Raymundo Soares, embora tenha Porto Alegre como localização, não é uma medida implementada pelo poder local, visto que foi criado no âmbito do projeto "Direito à memória e à verdade", executado pela Comissão da Anistia a partir de 2008, prevendo a instalação de memoriais em todas as capitais brasileiras. Sua instalação cumpre, sem dúvidas, um papel importante no que se refere à materialização de medidas contra o esquecimento e promotoras da memória sobre a ditadura. $\mathrm{O}$ monumento, no entanto, padece de problemas semelhantes ao que foi inaugurado em 1995.

Primeiro, devido à sua localização. $\mathrm{O}$ monumento alusivo ao "Caso das mãos amarradas" foi instalado no mesmo parque (Marinha do Brasil), também em área cujo trânsito de pessoas não é tão intenso, uma vez que se trata de um espaço aberto, em meio ao tráfego das avenidas que ladeiam o local. Segundo, porque a mera existência de um lugar destinado à memória das vítimas não significa que as pessoas que circulam no local irão, necessariamente, parar para ler a placa que "explica" a razão de ser do monumento. É difícil, nesse sentido, medir o alcance da obra-monumento junto à população. Passados quase 10 anos da sua inauguração, não há dados que permitam saber como ela é vista pelas pessoas que passam pelo local, tampouco pode-se saber quantas pessoas sabem da sua existência.

A identificação do "Dopinha", como é referido com frequência o casarão do Bairro Independência no qual o centro clandestino da repressão funcionou na década de 1960 e até o início dos anos 1970, foi algo marcante. Ocorrida no mesmo momento em que se iniciavam os trabalhos da Comissão Nacional da Verdade, em maio de 2012, a identificação do local serviu como ponto de convergências para vários setores da sociedade civil e militantes dos direitos humanos que se organizavam (alguns há décadas) em torno da luta por memória, verdade e justiça.

A partir da denúncia da descoberta do local, foi estabelecida uma disputa entre organizações da sociedade civil e os proprietários do imóvel. Em 2013, após uma série de negociaçóes, a proposta era que o casarão seria desapropriado e adquirido, numa parceria entre Prefeitura Municipal e Governo do Estado, e destinado à instalação e criação de um centro de memória (OLIVEIRA, 2013). Na ocasião, a ministra Maria do Rosário, da Secretaria de Direitos Humanos da Presidência da República, apoiou a 
medida, e movimentos de direitos humanos, como o Comitê Carlos de Ré, chegaram a projetar a inauguração do centro para março de 2014.

Os desdobramentos do caso, contudo, foram, no mínimo, frustrantes. Após promessas e negociaçóes envolvendo o poder municipal e estadual, a troca de governantes a partir de 2015 (no estado) e 2017 (no município) e as mudanças na conjuntura política do país impactaram negativamente o tratamento da questão. Atualmente, janeiro de 2021, o casarão onde funcionou o "Dopinha" continua fechado pelos seus proprietários, e a proposta de criação do memorial não saiu do papel.

Voltando à discussão em torno do nome da Avenida Castelo Branco, ocorre que tal discussão seria reativada em 2014, ano marcado pela passagem dos 50 anos do golpe de 1964. É nesse contexto em que ganharam destaque as diferentes memórias existentes sobre o período ditatorial, que Pedro Ruas e Fernanda Melchionna, ambos vereadores do PSOL/RS, apresentaram o Projeto de Lei (PL) 001/2014, com vistas à alteração do nome do logradouro para Avenida da Legalidade e da Democracia. Seria uma homenagem ao movimento liderado por Leonel Brizola em 1961, quando, após a renúncia do presidente Jânio Quadros, houve uma tentativa, por setores da direita, de impedir a posse do vice-presidente João Goulart no cargo (RUAS e MELCHIONNA, 2014).

Em linhas gerais, o PL 001/2014, além de fazer referência expressa às disposiçóes da Diretriz 25 do PNDH-3, apresentava a seguinte justificativa para a troca de nome da avenida:

Em contraponto à exaltação dos abusos cometidos no passado, o exercício de rememoração deve auxiliar na consolidação de nossa incipiente democracia, valorizando as lutas em sua defesa e resgatando a consciência histórica. A ressignificação de espaços públicos possui o condão de reafirmar o compromisso com os valores democráticos vigentes e sinaliza, de forma consciente, a ideia de náo repetição dos abusos cometidos durante a ditadura civil-militar. (RUAS e MELCHIONNA, 2014, p. 03).

O processo legislativo visando à alteraçáo do nome da avenida foi marcado por tensóes entre os vereadores que apoiavam o projeto, vinculados essencialmente a partidos políticos situados à esquerda e ao centro do espectro político partidário (o projeto angariou apoio de vereadores do PT, PCdoB, PDT, PTB, PMDB, PSD, entre outros), e aqueles que foram contrários à medida, os vereadores de partidos como o PP, DEM e PSDB, cujas bancadas votaram contra a aprovação do PL. 
Após meses em trâmite, o PL 001/2014 foi aprovado pela maioria dos vereadores na Câmara Municipal de Porto Alegre em 27 de agosto de 2014 (21 votos favoráveis, 5 contrários). A sanção do PL foi realizada em $1^{\circ}$ de outubro pelo presidente da Câmara, o vereador Mauro Pinheiro (PT/RS), tendo em vista que o prefeito José Fortunati ${ }^{4}$ (PDT/RS) optou por não se posicionar nem a favor nem contra a medida. Acompanharam a sessão na qual foi promulgada a lei, comemorando o resultado, vítimas da ditadura e militantes políticos de organizaçóes que lutam pelos direitos humanos e pelo resgate da memória do período (PROJETO..., 2014).

Longe de ser encerrada com a aprovação do PL, que passou a vigorar com a promulgação da Lei Ordinária 11.688/2014, a polêmica sobre a troca do nome persistiria nos anos seguintes. Em fevereiro de 2016, a vereadora Mônica Leal ${ }^{5}$ (PP/RS), ainda inconformada com a alteração, apresentou o PL 040/2016 propondo a revogação da lei aprovada em 2014 (SCOMAZZON, 2016). A justificativa da vereadora, em síntese, era a de que a troca do nome havia sido concretizada descumprindo procedimentos técnico-jurídicos do regimento interno da Câmara de Vereadores. Conforme consta na exposição de motivos do PL, a vereadora afirmava que:

Considerando que a Avenida Presidente Castelo Branco é uma via de acesso a Porto Alegre já institucionalizada e do conhecimento da população, a modificação de seu nome significa a descaracterização de um importante ponto de referência para os porto-alegrenses e para todas as pessoas que adentram a nossa Capital utilizando essa alternativa viária.

É verdade sabida que os movimentos históricos fazem parte de toda e qualquer sociedade. As figuras emblemáticas que influenciaram a construção do Brasil e de nossa Capital devem e precisam ser lembradas. O que foi consolidado ao longo do tempo não pode ser apagado de nossos livros e alijado de nossa biografia por razóes ideológicas ou políticopartidárias. (LEAL, 2016, p. 4).

\footnotetext{
${ }^{4}$ Importante mencionar que José Fortunati, prefeito de Porto Alegre entre os anos de 2010 e 2016, passou a maior parte de sua trajetória política filiado a partidos de esquerda (esteve no PT desde a década de 1980 até 2002) e centro-esquerda (esteve no PDT entre 2002 e 2017). Em 2018, teve uma breve passagem pelo PSB, posteriormente filiou-se ao PTB, e, atualmente, está no PROS. Fortunati foi eleito prefeito de Porto Alegre em 2012, mas estava no cargo desde 2010, após a renúncia de José Fogaça, que se afastou da Prefeitura para concorrer ao Governo do Estado nas eleiçóes de 2010.

${ }^{5}$ A vereadora Mônica Leal é filha de Pedro Américo Leal (1924-2016), militar de carreira (do Exército) e político que participou ativamente da ditadura no Rio Grande do Sul desde o Golpe de 1964. Durante o regime autoritário, Pedro Américo Leal exerceu diversos cargos parlamentares enquanto filiado à ARENA, partido de sustentação do regime autoritário, atuando posteriormente no PP/RS.
} 
Fora da arena legislativa municipal, e antes da apresentação do PL que visava à revogaçáo da troca do nome da avenida, a vereadora Mônica Leal, acompanhada pelos vereadores João Carlos Nedel (PP/RS) e Reginaldo Pujol (DEM/RS), ingressou com uma ação na justiça estadual gaúcha, alegando irregularidades no processo legislativo que resultou na aprovação da Lei 11.688/2014. Após tramitarem recursos e chegar até o Tribunal de Justiça do Estado do Rio Grande do Sul, sediado em Porto Alegre, a causa foi encerrada recentemente. Nela, foi ratificado pela maioria dos desembargadores que participaram do julgamento o argumento de que o projeto que deu origem à mudança na denominação do logradouro havia descumprido, em 2014, exigências técnicas previstas no regimento da Câmara de Vereadores (teria sido descumprido o quórum mínimo para a votação, entre outras questôes). Com a decisão dada em segunda instância, em setembro de 2018 o nome da avenida voltou a ser Avenida Presidente Castelo Branco (MATOS, 2018).

Importante notar que, nesse momento, quando a lei foi revogada pelo Tribunal de Justiça, vivia-se o auge de uma conjuntura política turbulenta, longe de ser considerada como um período de "normalidade democrática". Era o último ano do Governo Temer (2016-2018), iniciado após a deposição, mediante golpe parlamentar, da presidenta Dilma Rousseff (PT). Foi um ano no qual o ex-presidente Luiz Inácio Lula da Silva foi condenado à prisão, em janeiro, num julgamento marcado por dubiedades, sendo preso no mês de abril e ficando impossibilitado de concorrer às eleiçóes presidenciais. Foi um ano marcado, ainda, pelo aprofundamento das tensóes entre setores progressistas e setores de extrema-direita. Setores estes que vinham se articulando de forma acelerada e crescente desde junho de 2013, e, que, nas eleiçôes de outubro, ajudariam a eleger para a Presidência Jair Bolsonaro (eleito pelo PSL, atualmente sem partido), um político que se manifesta frequentemente contra os direitos humanos e em defesa da ditadura.

\section{Conclusão}

Inseridas num contexto de medidas que têm sido enquadradas nos estudos sobre justiça de transição, as políticas de memória visam contribuir para que, após um período autoritário e/ou marcado por massivas violaçóes aos direitos humanos, seja possível estabelecer as bases para um regime democrático estável, que repare as vítimas da violência praticada pelo Estado e preserve a memória sobre tais atos. Embora ganhem destaque as medidas implementadas em larga escala, ou seja, aquelas cuja abrangência se dá em nível nacional, medidas locais contra o esquecimento dos crimes 
cometidos durante ditaduras também existem e podem contribuir para o fortalecimento de um regime político pautado na defesa dos direitos humanos. A mudança no nome de logradouros ou instituições públicas que fazem alusão e/ou homenageiam fatos e pessoas vinculadas a um regime autoritário, como visto, constitui uma política de memória possível de ser realizada em âmbito local.

Conforme proposto, a análise dos fatos ocorridos na cidade de Porto Alegre entre 2014 e 2018 permitiu tecer algumas reflexôes sobre o modo como foram realizadas políticas de memória em âmbito local. Qual a relação do que foi exposto neste artigo com o processo de transiçáo à democracia levado a cabo no contexto brasileiro? Respondendo parcialmente ao questionamento formulado, acredita-se que os fatos envolvendo o processo legislativo que havia alterado a denominaçáo de uma das principais vias de acesso à capital dos gaúchos podem ser analisados considerandose: 1) duas constataçôes sobre políticas de memória, 2) o processo de transição à democracia no Brasil e seu impacto na construçấo da nova ordem política, 3) as mudanças de conjuntura política de 2014 a 2018.

No tocante às constataçóes sobre políticas de memória, os acontecimentos descritos evidenciam dois aspectos inerentes às medidas deste tipo, mas que, via de regra, podem passar despercebidos. Primeiramente, pode-se observar que políticas de memória são, em essência, políticas públicas que, embora possíveis de serem concretizadas, muitos governos não consideram uma tarefa essencial a ser cumprida por suas gestóes. Isto fica visível, no caso porto-alegrense, quando se observa que a lei que alterava o nome da avenida foi sancionada pelo presidente da Câmara de Vereadores, uma vez que o prefeito da cidade optou por não se manifestar sobre o PL que havia sido aprovado.

Um segundo aspecto que, com frequência, passa despercebido no que tange às políticas de memória, se relaciona a algo factível: políticas de memória não constituem conquistas irrevogáveis. Por mais que seja improvável que em alguns contextos medidas que resgatem, preservem e promovam a memória de acontecimentos traumáticos sejam revogadas, é possível que isto ocorra. Seja por ação encabeçada pelo Poder executivo. Seja por iniciativa do Poder Legislativo, com a mobilização de parlamentares. Seja via Poder Judicial.

Ainda que parcialmente, é possível entender os recuos descritos neste artigo observando-se tanto o modo como ocorreu o fim da ditadura no país (uma transição altamente controlada), assim como refletindo-se sobre os legados autoritários que se mantêm no presente e as mudanças conjunturais no cenário político recente. No que 
se refere aos legados autoritários, esses se manifestaram no âmbito da própria institucionalidade democrática quando, por exemplo, vereadores filiados ao $\mathrm{PP}$ e ao DEM, ambos partidos políticos herdeiros da ARENA, não satisfeitos com a derrota na votação do PL apresentado pelos vereadores do PSOL, encabeçaram as tentativas de revogaçáo da lei aprovada na Câmara Municipal de Porto Alegre. É algo bastante sintomático, uma vez que, com o fim da ditadura, políticos que atuavam em nome do regime simplesmente continuaram exercendo seus mandatos e filiaram-se em novos partidos, como se não houvesse qualquer diferença ser parlamentar numa democracia ou numa ditadura.

A vereadora Mônica Leal, conforme mencionado, é filha de um militar que esteve do lado dos setores responsáveis pela deposição do presidente João Goulart e apoiou a ditadura iniciada a partir de 1964. A participação de pai e filha na política brasileira pós-redemocratização também serve para demonstrar a força de alguns legados da ditadura, uma vez que, como parte dos pactos que foram articulados durante o processo transicional, às elites militares e políticas que sustentaram o regime autoritário foi garantida sua sobrevivência como atores com poder de veto no novo contexto político (ARTURI, 2001).

Legados autoritários se manifestaram, ainda, na forma como as polêmicas foram conduzidas em torno da aprovação da lei. A tentativa de barrar a aprovação da medida se dá, num primeiro momento, mediante a instrumentalização de elementos discursivos típicos de uma cultura autoritária que se manteve mesmo com o fim da ditadura. $\mathrm{O}$ apelo que é feito pelos vereadores contrários à mudança de nome da avenida, neste sentido, é baseado tanto na ideia de que o passado náo pode ser modificado por interesses ideológicos assim como na defesa de que o Governo Castelo Branco (1964-1967) impediu que o país entrasse em colapso. É a reprodução, cinquenta anos após o Golpe, de fragmentos de um discurso segundo o qual a sociedade brasileira seria ameaçada por elementos ideologicamente indesejáveis a serem combatidos.

Soma-se ao que foi mencionado, ainda, as mudanças de conjuntura no período de 2014 a 2018. Em 2014, quando o PL 001/2014 tramitou e foi aprovado pelos vereadores de Porto Alegre, vivia-se um contexto de aparente normalidade democrática. Havia uma Comissão Nacional da Verdade atuando. Era um contexto marcado, apesar dos limites, pelo debate sobre os 50 anos do Golpe. Em 2018, quando a decisão do Tribunal de Justiça foi finalmente emitida, vivia-se a polarização que marcou as últimas eleições presidenciais no país, que elegeu para o cargo um político que defende 
publicamente a tortura e questiona, de forma reiterada, o caráter autoritário da ditadura.

Os elementos aqui identificados, acredita-se, ajudam a entender parte dos motivos pelos quais uma política de memória como a que havia sido implementada em Porto Alegre pode vir a ser revertida. Se as políticas de memória em âmbito nacional são necessárias para garantir a não-repetição, o mesmo pode ser dito para as políticas em âmbito local. Embora desejáveis, políticas que visam o tratamento do saldo da repressão praticada por uma ditadura são difíceis de serem realizadas se o sistema político e, é claro, seus agentes, não estão dispostos a fazê-lo. A falta de incentivos e disposição para torná-las realidade talvez seja o principal alerta para o fato de que impedir o conhecimento do passado afeta direta e dramaticamente o futuro das democracias.

Carlos Artur Gallo é Doutor em Ciência Política pela Universidade Federal do Rio Grande do Sul, com Estágio Doutoral pela Universidade Complutense de Madri. Professor do Departamento de Sociologia e Politica da Universidade Federal de Pelotas. E-mal: galloadv@gmail.com

\section{Referências}

AMBOS, Kai. El marco jurídico de la justicia de transición. In: AMBOS, Kai; MALARINO, Ezequiel; ELSNER, Gisela (Eds.). Justicia de transición: con informes de América Latina, Alemania, Italia y España. Montevideo: Fundación Konrad-Adenauer, 2009. p. 23-129.

ARTURI, Carlos S. O debate teórico sobre mudança de regime político: o caso brasileiro. Revista de Sociologia e Política, n. 17, p. 11-31, 2001. doi: 10.1590/S0104-44782001000200003

BAUER, Caroline Silveira. Um lugar de memória no esquecimento: o monumento aos mortos e desaparecidos políticos em Porto Alegre. Revista Memória em Rede, v. 7, n. 13, p. 58-68, 2015. doi: 10.15210/rmr.v7i13.6305

BRASIL. Lei no 12.528, de 18 de novembro de 2011. Cria a Comissão Nacional da Verdade no âmbito da Casa Civil da Presidência da República. Brasília, 2011. Disponível em: <http://www.planalto. gov.br/ccivil_03/_ato2011-2014/2011/lei/112528.htm>. Acesso em: 17 ago. 2021.

BRASIL. Decreto 7.177, de 12 de maio de 2010. Altera o Anexo do Decreto no 7.037, de 21 de dezembro de 2009, que aprova o Programa Nacional de Direitos Humanos - PNDH-3. Brasília, 2010. 
Disponível em: <http://www.planalto.gov.br/ccivil_03/_ato2007-2010/2010/decreto/d7177.htm>. Acesso em: 17 ago. 2021.

BRASIL. Lei no 10.521, de 18 de julho de 2002. Assegura a instalação de Municípios criados por Lei Estadual. Brasília, 2002. Disponível em: <http://www.planalto.gov.br/ccivil_03/leis/2002/ L10521.htm>. Acesso em: 17 ago. 2021.

BRASIL. Lei no 9.140, de 04 de dezembro de 1995. Reconhece como mortas pessoas desaparecidas em razão de participação, ou acusação de participação, em atividades políticas, no período de 2 de setembro de 1961 a 15 de agosto de 1979, e dá outras providências. Brasília, 1995. Disponível em: <http://www.planalto.gov.br/ccivil_03/leis/19140.htm>. Acesso em: 17 ago. 2021.

CODATO, Adriano. Uma história política da transição brasileira: da ditadura militar à democracia. Revista de Sociologia e Política, n. 25, p. 83-106, 2005. doi: 10.1590/S0104-44782005000200008

GALLO, Carlos Artur. A Comissão Nacional da Verdade e a reconstituição do passado recente brasileiro: uma análise preliminar da sua atuação. Estudos de Sociologia, v. 20, n. 39, p. 327-345, 2015.

GALLO, Carlos Artur; GUGLIANO, Alfredo Alejandro. Legados autoritários, políticas de memória e qualidade da democracia no Brasil. In: GALLO, Carlos Artur; RUBERT, Silvania (Org.). Entre a memória e o esquecimento: estudos sobre os 50 anos do golpe civil-militar no Brasil. Porto Alegre: Deriva, 2014. p. 285-301.

GUGLIANO, Alfredo Alejandro; GALLO, Carlos Artur. On the ruins of the democratic transition: human rights as an agenda item in abeyance for the Brazilian democracy. Bulletin of Latin American Research, v. 32, n. 3, p. 325-338, 2013. doi: 10.1111/blar.12034

HALBWACHS, Maurice. A memória coletiva. São Paulo: Centauro, 2006.

HUNTINGTON, Samuel. A terceira onda: a democratização no final do século XX. São Paulo: Ática, 1994.

JELIN, Elizabeth. La lucha por el pasado: cómo construimos la memoria social. Buenos Aires: Siglo Veintiuno, 2017.

LEAL, Mônica. PLL 040/2016. Porto Alegre, 2016. Disponível em: <https://www.google.com/url?sa $=t \& r c t=j \& q=\& e s r c=s \&$ source $=$ web $\& c d=\& v e d=2 a h U K E w i b 4 e q P v r j y A h X C H r k G H Z N m A q 8 Q F n o$ ECAIQAQ\&url=http\%3A\%2F\%2Fwww.camarapoa.rs.gov.br\%2Fdraco\%2Fprocessos\%2F 127855 \%2FPLL_040-

16_M\%25C3\%2594NICA_LEAL_Revoga_Avenida_Legalidade.doc\&usg=AOvVaw0Z3_GDuUap 5HaYGFrdZflL >. Acesso em: 17 ago. 2021.

MATOS, Eduardo. TJ confirma que Avenida da Legalidade e da Democracia voltará a ser chamada de Castelo Branco. Gaúcha ZH, 30 ago. 2018. Disponível em: <https:/gauchazh.clicrbs.com.br/portoalegre/noticia/2018/08/tj-confirma-que-avenida-da-legalidade-e-da-democracia-voltara-a-serchamada-de-castelo-branco-cjlhaon9n05qo01qkictn1837.html>. Acesso em: 20 jan. 2021.

MENEGHETTI, Marcus. Vereadores vetam mudança em nome da Castelo Branco. Jornal do Comércio, 15 dez. 2011. Disponível em: <https:/www.jornaldocomercio.com/site/ noticia.php?codn=81482>. Acesso em: 20 jan. 2021.

NATUSCH, Igor. "Caso das mãos amarradas" ganha memorial em Porto Alegre. Sul21, 27 ago. 2011. Disponível em: <https://sul21.com.br/noticiasultimas-noticiaspolitica/2011/08/caso-das-maosamarradas-ganha-memorial-em-porto-alegre/>. Acesso em: 20 jan. 2021. 
OLIVEIRA, Samir. Fortunati e Tarso transformarão antigo Dopinha em memorial contra a ditadura. Rede Brasil Atual, 19 dez. 2013. Disponível em: <https:/www.redebrasilatual.com.br/cidadania/ 2013/12/fortunati-e-tarso-se-comprometem-a-transformar-antigo-dopinha-em-memorial-contra-aditadura-5649/>. Acesso em: 20 jan. 2021.

PEREIRA, Anthony W. Ditadura e repressáo: o autoritarismo e o Estado de direito no Brasil, no Chile e na Argentina. Rio de Janeiro: Paz e Terra, 2010.

PORTO ALEGRE. Lei Ordinária $n^{\circ} 11.688$, de $1^{\circ}$ de outubro de 2014. Altera a denominação da Avenida Presidente Castelo Branco para Avenida da Legalidade e da Democracia. Porto Alegre, 2014. Disponível em: <https://leismunicipais.com.br/a1/rs/p/porto-alegre/lei-ordinaria/2014/1169/11688/ lei-ordinaria-n-11688-2014-altera-a-denominacao-da-avenida-presidente-castelo-branco-paraavenida-da-legalidade-e-da-democracia>. Acesso em: 17 ago. 2021.

PROJETO de lei é promulgado e Avenida Castelo Branco dá lugar à Avenida da Legalidade e Democracia. Sul21, 1 out. 2014. Disponível em: <https://sul21.com.br/cidades/2014/10/111 projeto-de-lei-e-promulgado-e-avenida-castelo-branco-da-lugar-a-avenida-da-legalidade-edemocracia/>. Acesso em: 20 jan. 2021.

QUINALHA, Renan. Justiça de transição: contornos do conceito. São Paulo: Outras Expressôes; Dobra Editorial, 2013.

RECONDO, Felipe. Tanques e togas: o STF e a ditadura militar. São Paulo: Companhia das Letras, 2018.

RICOEUR, Paul. A história, a memória, o esquecimento. Campinas: Edunicamp, 2007.

RUAS, Pedro; MELCHIONNA, Fernanda. PL $n^{o}$ 001/14. Porto Alegre, 2014. Disponível em: <http://200.169.19.94/processo_eletronico/000462014PLL/000462014PLL_PROJETO_5169903 6_578.pdf>. Acesso em: 20 jan. 2021.

SCOMAZZON, Carlos. Projeto revoga troca de nome da Castelo Branco para Avenida da Legalidade. [Portal da Câmara Municipal de Porto Alegre], 24 mar. 2016. Disponível em: <https://www.camarapoa.rs.gov.br/noticias/projeto-revoga-troca-de-nome-da-castelo-branco-paraavenida-da-legalidade>. Acesso em: 20 jan. 2021.

SOLÍS DELGADILLO, Juan Mario. Los tiempos de la memoria en las agendas políticas de Argentina y Chile. Buenos Aires: Eudeba, 2015.

Texto recebido em 20 de janeiro de 2021. Aprovado em 15 de julho de 2021. 